\title{
The effect of the placement of the product in film: Consumers' emotional responses to humorous stimuli and prior brand evaluation
}

Received (in revised form): 5 July, 2007

\section{ChangHyun Jin}

is a fellow researcher in the Institute for Communication and Information at the Hankuk University Foreign Studies in Korea. He received a PhD in advertising from the University of Florida and an MA in advertising from the University of Texas.

\section{Jorge Villegas}

is an assistant professor in the Department of Advertising, College of Journalism and Communications, University of Florida. His main research interest is the influence of affect in commercial or health-related messages communicated via traditional or interactive media. His work has been published in Health Education Research, Schizophrenia Bulletin, Journal of Non Profit \& Public Sector Marketing, Proceedings of the American Academy of Advertising, and a chapter in the Advertising and Consumer Psychology Book Series. He has received research awards from organisations like the American Academy of Advertising as well as participated as a member of research teams sponsored by the National Institute of Mental Health and the Defense Threat Reduction Agency.

\section{Keywords product placement, humour, emotional response, prior brand evaluation}

\begin{abstract}
This study explores the role of prior brand evaluation and the placement of the product in humorous movies on the consumer judgment stage, investigating their effects on consumer response. The findings of the study indicate that the placement of product in humorous movie scenes result in positive emotional responses from consumers. In addition, prior brand evaluation was found to play an important role in post-decision-making processes, such as purchasing behaviour. It is anticipated that the analysis resulting from this valuable study will provide a reference for further empirical and theoretical studies on the use of the placement of the product in movies as an alternative to advertising and other marketing communications strategies.
\end{abstract}

Journal of Targeting, Measurement and Analysis for Marketing (2007) 15, 244-255. doi:10.1057/palgrave.jt.5750049

\section{INTRODUCTION}

Marketers and advertisers have sought effective strategies for conveying brand image via different media outlets. Although product placement is recognised as an alternative to traditional ads, there are significant pros and cons regarding the overall effectiveness of product placement.

\footnotetext{
Correspondence: ChangHyun Jin, Institute for Communication and Information, Hankuk University of Foreign Studies, 130-791, 270 Imun-dong Dongdaemun-Gu, Seoul, Korea.

Tel: + 81221732544 ;

Fax: +81 221733158 ;

E-mail: mokhosa@gmail.com
}

Previous studies on product placement have focussed on how product usage influences the consumer after viewing movies containing product placements. Despite the potential impact of effective product placements, little is, however, known about the effects of the placement of the product in humorous movies or the relationship between prior brand evaluation and consumer attitude formation following exposure to the placement of product in movies.

Product placement, or the promotional tactic used by marketers and advertisers in which real commercial products appear in a fictional play, film or television show, was spotlighted by 
marketers and advertising agencies as an alternative advertising strategy. The most common form of product placement occurs in film and television.

An effective product placement relies on an understanding of consumer responses to products based on cognition and affection. Previous research on the impact of humorous product placements provides some useful insight into this study.

Thus, the purpose of this study is: (1) to assess the role of prior brand evaluation and the placement of the product in humorous movies on the consumer judgment stage; (2) to provide information on what role humorous scenes play in affecting consumer emotions and behaviour and (3) to investigate consumers affection responses to the placement of the product in humorous films.

\section{THEORETICAL AND EMPIRICAL BACKGROUND}

\section{Product placement}

Aaker ${ }^{1}$ differentiated sponsorship into two types, nonmedia sponsorship and mass programme sponsorship, while Meenaghan ${ }^{2}$ focussed on sports and event sponsorship. Product placement could be a form of mass-media programme sponsorship, since product placements can be combined with special promotions to publicise a brand's entertainment tie-ins. ${ }^{3}$ The fundamental goal of product placement is to introduce new products and demonstrate product use. Thus, companies try to gain exposure for their products through product placement because it has the ability to deliver positive messages in a noncommercial setting.

Previous research based product placement categorisations on diverse criteria, studying the effectiveness of different classifications of product placements. Although results varied depending on the types of products advertised and their media appearances, research generally suggested that product placement positively influenced consumer attitudes, recall and recognition towards brands appearing in movies. Gupta and Lord ${ }^{4}$ examined the impact of product placement on consumer recall in terms of different types of product placement, such as 'prominence/subtlety' and 'audio-only/visual-only' presentations. Their results indicated that products featured prominently yielded higher consumer recall when compared to television commercials and moresubtle product appearances. Furthermore, consumers could better recall products referenced in audio messages than those seen in visual appearances.

Brennan et al. ${ }^{5}$ examined audiences' recognition of product placement depending on the type of product placement and its exposure time.

Regarding the effectiveness of product placement types, the results of their study mirrored those of Gupta and Lord ${ }^{6}$, which suggested that prominent product placements proved more effectual than other methods of promoting consumer memory. Brennan et al. ${ }^{7}$ also found that product placement type had a greater influence on consumer recognition than the product's exposure time.

D'Astous and Seguin classified various types of product placement based on a product's congruity with a scene, its degree of appearance and its association with a movie star. Their findings showed that positive attitudes towards product placements were elicited in three different situations: (1) when the product appeared with a movie star; (2) when the product placement was congruent with a scene presented and (3) when the product was shown prominently. ${ }^{8}$ Although product placements in movie scenes garnered positive consumer attitudes towards the products, however, they reduced consumer recall and brand recognition. Additional research has found that consumer attitudes and memory are similarly influenced by product placements in television programmes and video games. ${ }^{9-11}$

A limited number of studies have investigated the impact of product placement on consumers' purchase intentions. ${ }^{12-14}$ Baker and Crawdoed ${ }^{15}$ found that consumers had a higher level of shortterm purchase intention for products embedded in movies. Additionally, the studies of Gould et al. ${ }^{16}$ and Karrh et al. ${ }^{17}$ supported the result that product placement positively influenced purchase intention. Some researchers argue that there is a correlation between consumer evaluation and 
purchase intention, or that consumer brand usage and evaluation may affect post-purchase behaviours.

\section{Emotional response as affect}

Affect is another important component of consumer attitude and a force in persuasion. Affect is defined as a consumer's feelings or emotions towards an object. Lazarus ${ }^{18}$ identifies emotion as a reaction to meaning, and if the meaning is changed there will also be a change in the subsequent emotion (p. 830). Holbrook and Shaughnessy's ${ }^{19}$ work contrasted thinking aspects, or 'logical, objectively verifiable descriptions of tangible product features' with the feeling aspects in advertising, or 'emotional, subjective impressions of intangible aspects of the product' (p. 547). Both meanings are contained in virtually any type of communication, with only their relative balance varying. This balance may be assessed through content analysis to predict or explain advertising effects. ${ }^{20}$

Detenber et al., adopt a dimensional view of emotion, ${ }^{21-23}$ citing arousal, hedonic valence and dominance as the three dimensions of emotion. Typically, emotion researchers characterise the valence dimension as a continuous range of affective response extending from pleasant or positive valence at one pole, to unpleasant or negative valence at the other. The dimension of autonomic arousal is characterised by a continuous response ranging from energised, excited and alert to calm, drowsy or peaceful. These two dimensions, valence and arousal, account for most of the explained variance in emotional responses. ${ }^{24}$ This dimensional view of emotion was identified in a study designed to explore the relationship between image motion and emotional responses to pictures. Specifically, the study focussed on whether or not image motion had a positive effect on emotional arousal as indexed by self-reports.

Thus, feelings are not treated as antecedent states like they have been in many extant models of advertising effects. Some researchers argued that consumer feelings can be activated quickly through nonverbal elements in an ad, and therefore that feelings can be generated by the ad itself. Thus, the cognitive system of processing advertisements can be separated from the affective system in the study of advertising effects. ${ }^{25}$

\section{The effect of humour on consumer responses}

Humour is one of the most commonly employed communications strategies in advertising. Research on how people process humorous images (eg picture and scenes) has been studied in terms of consumer behaviour. ${ }^{26-28}$ Humour appropriate for the product category that is well integrated with a message's themes has been shown to enhance attention, credibility, recall, evaluation and purchase intention. ${ }^{29-33}$ Humour also appears to increase the transfer of positive affect from an ad to a brand name. ${ }^{34,35}$ Finally, researchers have identified several moderators of humour's effect on processing outcomes, including nonmessage factors $^{36}$ (eg prior brand attitude), product characteristics ${ }^{37}$ (eg involvement) and audience characteristics $^{38}$ (eg knowledge).

The fundamental goal of humour is to increase comprehension of an $\mathrm{ad}^{39}$ yield positive consumer attitudes towards an $\mathrm{ad}^{40-42}$ and therefore enhance consumer attitudes towards the advertised product. ${ }^{43}$ Many researchers also emphasise that the use of humour effectively calls attention to an advertisement. ${ }^{44-46}$ The use of puns, understatements, jokes, ludicrous situations, satire and irony could be particularly appropriate in humorous ad campaigns for low-involvement products, ${ }^{47,48}$ which rely heavily on generating positive consumer feelings about an ad. Kelly and Solomon ${ }^{49}$ identified comical action, exaggeration, the use of puns, irony, satire and personification as characteristics that differentiate humorous ads from general advertisements.

\section{Prior brand evaluation}

An individual's prior evaluation of the attitude object is a primary determinant of the evaluative directionality of information processing, and that favourable prior evaluations are closely related to consumer attitudes towards ads and brands. Thus, prior brand evaluation is an important pragmatic consumer characteristic. ${ }^{50,51}$ These studies also 
noted that the use of prior brand evaluation to segment markets is especially important since advertising can directly influence a consumer's evaluation of a brand. ${ }^{52}$ Chattopadhyay and Basu ${ }^{53}$ also found that subjects with positive prior evaluations had a higher probability of choosing the advertised brand when exposed to a humorous ad. Humour, therefore, may positively affect consumer emotion and play an important role in reducing negative consumer attitudes towards a target brand. $\mathrm{Wu}$ and Shaffer ${ }^{54}$ argued that consumers with direct versus indirect brand experience will differ in their susceptibility to a counter attitudinal message. Consequently, an attitude formed from direct experience is believed to be more clearly and confidently held than an attitude formed on the basis of hearsay (Dean and Biswas, ${ }^{55}$ p. 45). Thus, prior brand usage and evaluation are closely associated with consumer post-decision-making processes, such as purchase intention.

\section{Hypotheses}

Emotions can also play a fundamental role in the purchase or consumption of an entire product category if the product plays an emotional role in the consumer life. An emotional tone in an advertisement can draw attention to a message, make it memorable or illustrate the product benefits in action. Appropriately themed advertising appears to imbue some brands with a subjective vividness or an authenticity that comparable competitors lack. When a brand name is consistently presented in conjunction with the evocation of an emotion, the brand name itself will, over time, evoke an emotional response (Zeitlin and Richard, ${ }^{56}$ p. 34).

Thus, this investigation on the effects of humour on consumer attitudes formation leads to the following hypotheses:

$\mathbf{H}_{1}$ : Subjects exposed to product placements in humorous film scenes are likely to experience greater

(a) pleasure and

(b) arousal than subjects exposed to product placements in nonhumorous film scenes.
$\mathbf{H}_{2}$ : Subjects with positive prior brand evaluations are more likely to have higher

(a) pleasure and

(b) arousal than those have a negative prior brand evaluation.

Regarding the positive effects of humour on consumer emotions, the following hypothesis is posited:

$\mathbf{H}_{3}$ : Subjects exposed to product placements in humorous scenes versus those exposed to product placements in nonhumorous scenes, when they experience the more positive effect of pleasure and arousal are more likely to:

(a) exhibit more favourable attitudes towards product placement in movie;

(b) exhibit more favourable attitudes towards the placed target brand and

(c) exhibit higher purchase intention.

Given the literature on prior brand evaluation, people with positive prior brand evaluations have a higher probability of choosing the advertised brand when exposed to a humorous ad. The study of the relationships of viewers' prior brand evaluation in advertising showed that when a consumer's prior brand evaluation is favourable, a humorous ad is more effective in enhancing brand attitude and choice behaviour compared to nonhumorous ad. ${ }^{57}$ In the same context, consumer's prior brand evaluation seems to have some impact on the effectiveness of product placement. Previous research on the impact of humorous product placements provides some useful insight into this study. Thus, the previous discussion on the effect of prior brand evaluation leads to the following hypothesis:

$\mathbf{H}_{4}$ : Subjects with positive prior brand evaluations versus those with negative prior brand evaluation will have more:

(a) favourable attitudes towards product placement in movie; 
(b) favourable attitudes towards the placed target brand and

(c) positive purchase intentions.

Chattopadhyay and Basu ${ }^{58}$ argued that the role of prior brand evaluation as a moderator of the effects of humorous stimuli suggests that humorous stimulus receive more-extensive processing than nonhumorous stimulus (p. 468). Also people who are exposed to humorous stimulus are more likely to experience a greater persuasive impact than nonhumorous when they have a favourable prior brand evaluation. It is assumed that the effects of humorous product placements in films may be moderated by prior brand evaluation. Therefore, the following hypothesis is posited:

$\mathbf{H}_{5}$ : Prior brand evaluation and the valence dimension both affect the efficacy of humorous product placements in films. That is, a two-way interaction between two different types of humour or nonhumorous movie scenes and prior brand evaluation will exist on:

(a) pleasure;

(b) arousal;

(c) perception of product placement;

(d) attitude towards the placed brand and

(e) purchase intention, respectively.

\section{RESEARCH METHODOLOGY}

\section{Experimental design}

An experiment was conducted to assess the role of prior brand evaluation as a moderator of the effects of humorously placed product in a movie on attitude towards product placement, the brand and purchase intention. A $2 \times 2$ between-subjects design was used to test the proposed hypotheses (types of the product placement in the movie: humorous versus nonhumorous $x$ prior brand evaluation: positive and negative).

\section{Pilot study and pre-test for stimuli}

A pilot study was conducted to check the validity of the product placement in the movies and the samples of product placement were judged by three advertising professionals and one advertising scholar. The judges classified the product's placement in the movie as either humorous or nonhumorous.

To examine the effects of product placement on dependent variables, two different versions of a current movie for an existing donut company were edited by a professional designer. The movie scenes were specially selected for use as stimulus materials in the experiment. The movie segment contained the brand logo and package of the product place in the scenes of a movie where the product was consumed. Each group saw $1 \mathrm{~min}$ 30 s clips of products placed in movies. In another pilot study, a group of 40 subjects evaluated two different movie scenes on a scale ranging from 'not at all exciting, funny, and interesting' $(-3)$ to 'very exciting, funny, or interesting' $(+3)$. The results of the pilot study led to the framed humorous movie scene being chosen as the humorous placement stimulus $(x=2.22)$ and to the framed the no-humorous movie scene being played as the nonhumorous movie scene $(x=-1.34)$.

To manipulate prior brand evaluation, subjects were asked to participate in a study designed to examine two different information formats. Participants were asked to evaluate two different presentation formats (eg table of ingredients, and consumer report, market value, market share ranking and brand logo). Each format was for a different product category (two different donut companies). Subjects were told that the study was being conducted on behalf of Consumer Reports to find out how effective each presentation format was. Prior evaluation of the target donut brand was manipulated by giving an ostensible rating of either highly favourable $(+2)$ or highly unfavourable $(-2)$ to the target brand.

In addition, a pre-test was conducted to ensure that the directions and questions were clear and unambiguous as well as to check the dimension of independent and dependent variables before the actual experiment. After the pre-test, we compiled a list of unfamiliar words used in the questionnaire as well as worked with the directions to the experiment to make them clear. The primary objective of the pre-test was to ensure the video quality and sound. The video 
consisted of samples of product placement in movies lasting $1 \mathrm{~min} 30 \mathrm{~s}$ each. Exposure time was considered an important issue in this study because the movies contained various components that could arouse subjects' mental and psychological senses. Thus, the pre-test fixed the time schedule in the experiment to avoid subject bias.

\section{Independent variables}

The prior attitude measure consisting of three items such as quality, price and taste, was adapted from Chattopadhyay and Basu ${ }^{59}$ to determine the extent to which the participants attended to the slide presentation and stimuli. Humorous and nonhumorous target product placements in the movie were adapted through pilot studies and a series of pre-tests. Two product placements in the movie (two humorous versus nonhumorous movie scenes) were selected. They were based on real movies presented in major theatres in recent years.

\section{Procedure}

This experiment was designed to assess the role of prior brand evaluation and humorous product placement in movies on the consumer judgment stage and to investigate consumers' affection responses to humorous product placements in films.

Experiment procedure and questionnaires developed for this research were based on the respondent feedback regarding treatment stimuli, clarity of the questions and layout of the survey. A total of 185 undergraduate students, who enrolled in an advertising research class at a large southern university, participated in the experiment for extra course credit. A fortuitously accessible large population, students were considered appropriate subjects for the goal of this study, which examined the causal relationship between exposure to product placement in movies and responses to objects. Upon their arrival to different classrooms, subjects were given a packet entitled 'Donut Product Study'. After all the subjects received the booklet, the proctor asked them to write down the last four digits of their student identification numbers on the first page. To ensure that the testing procedures in two groups could be as similar as possible, the proctors followed detailed written directions. Subjects were instructed when to begin, when to stop and when to turn the page.

The second page contained information about the target brand from a product category in a particular format. The information about the products they had seen information was ostensibly provided by Consumer Reports. Then subjects were asked to evaluate the brand on the third page. After watching the edited movie segment, using a self-administered questionnaire, subjects started with an emotional response task, and proceeded to an attribute towards product placement task, the placed brand task and purchase likelihood task.

\section{Dependent variables}

The measurement tools used in this study are based on the literature review related to prior brand evaluation as independent variables. Four major theoretical constructs were examined. In addition, we used previously developed scales, modified when necessary, to measure the following variables: emotional response, attitude towards the product placement in the movie, attitude towards brand and purchase intention.

To measure emotional response, AdSAM and word scales were used in this study at the same time. The measure consisted of three different scales (abbreviated as PAD): pleasure, measures the positive/negative aspect of the feeling; arousal, the level of intensity or involvement in the feeling and dominance, the degree of empowerment the respondent feels. The Self-Assessment Manikin $(\mathrm{SAM})^{60}$ is a graphic character that is used to represent the three dimensions of PAD. Initially, SAM was compared to verbal PAD by using the catalogue of situations employed by Mehrabian and Russell ${ }^{61}$ to standardise the three PAD dimensions. The results indicated that SAM generated a similar pattern of scale values for these situations as was obtained for semantic differential scales. ${ }^{62}$

The research used previously developed scales, modified when necessary, to measure the variables in the study. Attitude towards product placement in movie was assessed utilising a four-item, sevenpoint semantic differential scale (bad/good, unfavourable/favourable, unpleasant/pleasant and 
likeable/unlikable). These semantic differential scales were used in this study to measure attitude towards product placement that were selected from various prior research studies.

Attitude towards the brand was assessed utilising a four-item, seven-point semantic differential scale (bad/good, unfavourable/favourable, negative/ positive and dislike/like). This attitude to the brand measure was used in prior research by MacInnis and Park. ${ }^{63}$ The author reports that 87.5 per cent of brand attitude can be accounted for by the scale in factor. The brand attitude scale was computed by the average of summed items.

Purchase intention was measured using Haley and Case's Verbal Purchase Intent Scale. ${ }^{64}$ The scale is a single-item Likert-type scale. Validity for this scale was be established by Gormly and Gruber. ${ }^{65,66}$ Also, Haley and Case $^{67}$ report that the verbal purchase intent scale had a high-factor loading on the product evaluation factor with a coefficient alpha of 0.88 . A significant reliability (test-retest) measure was also reported by Kassarjian and Nakanishi. ${ }^{68}$

\section{EXPERIMENTAL RESULTS}

The prior brand evaluation and formatted movie segment served as the two independent variables. Dependent variables were analysed by an analysis of variance (ANOVA).

\section{Manipulation check}

The manipulation check of humour measure consisted of three items to determine the extent to which the participants attended to the stimuli. For the manipulation for type of movie scenes, independent sample $t$-tests were performed. A $t$-test indicated that the intended manipulation could be successful. Thus, participants perceived the difference between humour and nonhumour $\left(\right.$ Mean $_{\text {humorous }}=4.37$, Mean $_{\text {nonhumorous }}=3.75$, $t=3.40, p \leqslant 0.05)$.

The manipulation check of prior brand evaluation measure consisted of four items adapted from Chattopadhyay and Basu ${ }^{69}$ to determine the extent to which the participants attended to the stimuli. A $t$-test indicated that the intended manipulation could be successful. For the manipulation for level of prior brand evaluation, independent sample $t$-tests were performed. The participants perceived the difference between positive and negative prior attitude towards the brand $\left(\mathrm{Mean}_{\text {positive }}=5.37\right.$, Mean $\left._{\text {negative }}=2.94, t=-17.7, p \leqslant 0.05\right)$. The interitem total-correlation coefficient value among the nine items for priori attitude towards the brand ranged from 0.67 to $0.90(p<0.01)$. Cronbach's alpha was 0.90 for prior brand evaluation.

Data were analysed using a MANOVA on the dependent variables. Given the use of humour in the movies as an affective stimulus, arousal and pleasure were used in this analysis due to their relation to emotion and humorously framed movie scenes. The dependent variables were attitude towards the brand and purchase intention. A $2 \times 2$ between-subjects factorial design was used (types of movie scenes: humorous and nonhumorous $\times$ positive and negative prior brand evaluation). Tables 1 and 2 illustrate MANOVA and ANOVA results, including means, standard deviations and Wilks' Lambda.

Hypotheses 1(a) and $1(\mathrm{~b})$ predicted that subjects who are exposed to the humorous product placement scenes are likely to have higher arousal and pleasure than those exposed to nonhumorous movie scene with the product. A subject's valence of emotions would therefore better explain results when subjects are exposed to the humorous product placement scene. Hypothesis 1 was supported $(\mathrm{F}[1,181]=11.9$, $p<0.001$ and $\mathrm{F}[1,181]=6.11, p<0.05)$. Hypotheses 2(a) and 2(b) predicted that subjects with positive prior brand evaluations are more likely to have higher pleasure and arousal than those that have a negative prior brand evaluation when brands are familiar. Hypothesis $2(\mathrm{a})$ was supported $(\mathrm{F}[1,181]=4.65, p<0.05)$, but $2 \mathrm{~b}$ was not supported $(\mathrm{F}[1,181]=0.50, p=0.48)$.

As seen, hypotheses 3(a), 3(b) and 3(c) predicted that subjects exposed to product placements in humorous scenes, versus those exposed to product placements in nonhumorous scenes, would exhibit more favourable attitudes towards product placement, attitude towards a brand and purchase intention. $\mathrm{H}_{3(\mathrm{a})}$ was supported $(\mathrm{F}[1,181]=5.57, p<0.05)$. The main effect of 
Table 1: Means and standard deviations by condition

\begin{tabular}{lllllll}
\hline Treatment & & Pleasure & Arousal & PPL & ATTB & PI \\
$\begin{array}{lllllll}\text { Prior brand } \\
\text { evaluation }\end{array}$ & $\begin{array}{l}\text { Types of movie } \\
\text { scenes }\end{array}$ & & & & & \\
\hline Positive & Humour & $6.5(1.9 / 58)^{*}$ & $5.1(1.6 / 58)$ & $4.6(1.6 / 58)$ & $4.3(1.6 / 58)$ & $4.7(1.6 / 58)$ \\
& Nonhumour & $5.7(1.6 / 35)$ & $5.2(1.9 / 35)$ & $4.5(1.2 / 35)$ & $4.2(1.2 / 35)$ & $4.2(1.4 / 35)$ \\
Negative & Humour & $5.4(1.9 / 49)$ & $4.6(2.2 / 49)$ & $4.1(1.9 / 49)$ & $4.8(1.7 / 49)$ & $5.5(1.2 / 49)$ \\
& Nonhumour & $4.8(1.8 / 43)$ & $4.0(1.6 / 43)$ & $4.2(1.6 / 43)$ & $3.7(1.5 / 43)$ & $3.6(1.6 / 43)$ \\
\hline
\end{tabular}

*Mean (Standard Deviation/Number).

Table 2: MANOVA results

\begin{tabular}{|c|c|c|c|c|c|}
\hline Treatments & & Wilks' Lambda & $\boldsymbol{F}$ & d.f. & $p$ \\
\hline Types of movie scenes & & 0.897 & 4.07 & & 0.05 \\
\hline Prior brand evaluation & Dependent variables & 0.827 & 7.39 & (1.181) & 0.05 \\
\hline Prior brand evaluation $\times$ types of movies & & 0.923 & 2.95 & & 0.05 \\
\hline
\end{tabular}

types of movie scenes (eg humorous and nonhumorous) was, however, not significant on perceptions of their attitude towards the brand $(\mathrm{F}[1,181]=0.037, p=0.85)$, nor was that for purchase intention $(\mathrm{F}[1,181]=0.186, p=0.67)$. Thus, $\mathrm{H}_{3(\mathrm{~b})}$ and $\mathrm{H}_{3(\mathrm{c})}$ were not supported.

Hypotheses 4(a), 4(b) and 4(c) predicted that subjects with positive prior brand evaluations, versus those with negative prior brand evaluation, would have more favourable attitudes towards product placement, towards a brand and purchase intention. As shown in Table 3, positive levels of prior attitudes towards the brand are associated with more favourable attitude towards a brand $(\mathrm{F}[1,181]=6.78, p<0.05)$ and more-positive purchase intention with the product $(\mathrm{F}[1$, $181]=4.65 p<0.05)$. Thus, $\mathrm{H}_{4(\mathrm{~b})}$ and $\mathrm{H}_{4(\mathrm{c})}$ were supported. The main effect of prior brand evaluation was, however, not significant on the perceptions of product placement in movie is $(\mathrm{F}[1,181]=0.809, p=0.37)$. Thus, $\mathrm{H}_{4(\mathrm{a})}$ was not supported (Figures 1 and 2).

Hypotheses $5(\mathrm{a})-5(\mathrm{e})$ predicted that there is a two-way interaction effect between prior brand evaluation and types of movie scenes on dependent variables, respectively. As shown in the Tables 2 and 3, the interaction effects are significant $($ Lamda $=0.92, F(1,181)=2.95$, $p<0.05)$. The types of movie scenes and level of prior brand evaluations were statistically significant for perception of attitude towards a brand and purchase intention $(\mathrm{F}[1,181]=4.96$, $p<0.05, \mathrm{~F}[1,185]=9.92, p<0.05)$, respectively. That is, a two-way interaction between types of movie scenes and level of prior brand evaluation was predicted to lead to an attitude towards a brand and purchase intention. There was, however, no interaction effect between prior brand evaluation and types of movie scenes on pleasure $(\mathrm{F}[1,181]=0.289, p=0.59)$, arousal $(\mathrm{F}[1,181]=$ $0.538, p=0.46)$ and perception of product placement $(\mathrm{F}[1,181]=0.086, p=0.77)$. Thus, $\mathrm{H}_{5(\mathrm{a})}$, $\mathrm{H}_{5(\mathrm{~b})}$ and $\mathrm{H}_{5(\mathrm{c})}$ were not supported.

\section{DISCUSSION AND LIMITATIONS}

This study's objective was to provide insight antecedents influencing prior attitudes on consumer attitude formation. Participants of this experiment were utilised to validate much of the hypothesised model and to suggest additional implications.

Consumer cognition and affection should be used in accomplishing effective product placement, and understanding consumer response to placement. This study can provide some useful insight for further research related to a similar 
Table 3: Results of between-subjects

\begin{tabular}{|c|c|c|c|c|c|}
\hline Independent variables & Dependent variables & MS & d.f. & $\boldsymbol{F}$ & $p$ \\
\hline \multirow[t]{5}{*}{ Types of movie scenes } & Pleasure & 23.3 & 1 & 11.9 & 0.05 \\
\hline & Arousal & 12.5 & 1 & 6.11 & 0.05 \\
\hline & $\begin{array}{l}\text { Attitude towards product } \\
\text { placement }\end{array}$ & 18.9 & 1 & 5.57 & 0.05 \\
\hline & Attitude towards the brand & 0.083 & 1 & 0.037 & 0.85 \\
\hline & Purchase intention & 0.382 & 1 & 0.186 & 0.67 \\
\hline \multirow[t]{5}{*}{ Prior brand evaluation } & Pleasure & 19.13 & 1 & 4.65 & 0.05 \\
\hline & Arousal & 1.02 & 1 & 0.50 & 0.48 \\
\hline & $\begin{array}{l}\text { Attitude towards product } \\
\text { placement }\end{array}$ & 2.02 & 1 & 0.809 & 0.37 \\
\hline & Attitude towards the brand & 15.2 & 1 & 6.78 & 0.05 \\
\hline & Purchase intention & 62.8 & 1 & 30.52 & 0.05 \\
\hline \multirow{5}{*}{$\begin{array}{l}\text { Prior brand evaluation } \\
\times \text { types of movie scenes }\end{array}$} & Pleasure & 0.567 & 1 & 0.289 & 0.59 \\
\hline & Arousal & 1.10 & 1 & 0.538 & 0.46 \\
\hline & $\begin{array}{l}\text { Attitude towards product } \\
\text { placement }\end{array}$ & 0.215 & 1 & 0.086 & 0.77 \\
\hline & Attitude towards the brand & 11.13 & 1 & 4.96 & 0.05 \\
\hline & Purchase Intention & 20.4 & 1 & 9.92 & 0.05 \\
\hline
\end{tabular}

aTypes of movie scenesxlevels of Prior Brand Evaluation.

Note: Scales for mean scores are from 1 to 7 with 7 being most positive $(n=185)$.

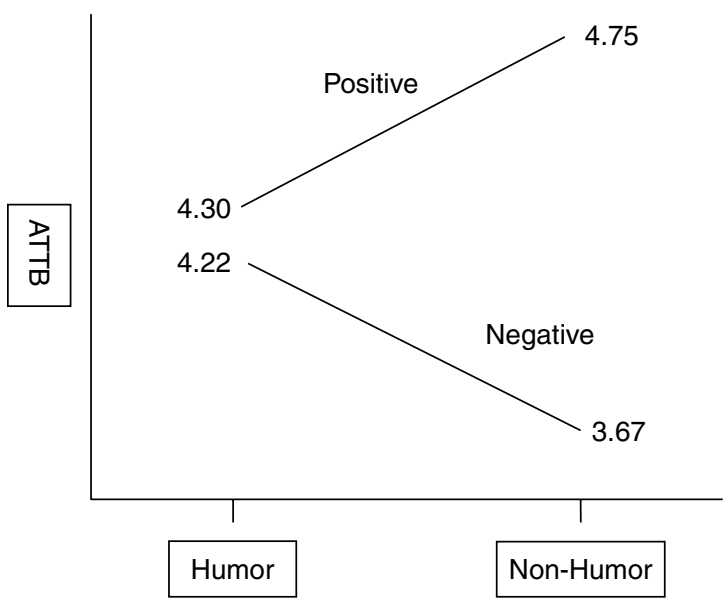

Figure 1: Attitude towards the brand positive versus negative prior brand evaluation

topic. We propose that the effects of placing a product in a movie are moderated by the background in the movie.

This study also examined the role of prior brand evaluation, emotional response, and consumer attitude formation such as attitudes towards the brand and purchase intention in the humorous versus nonhumorous product

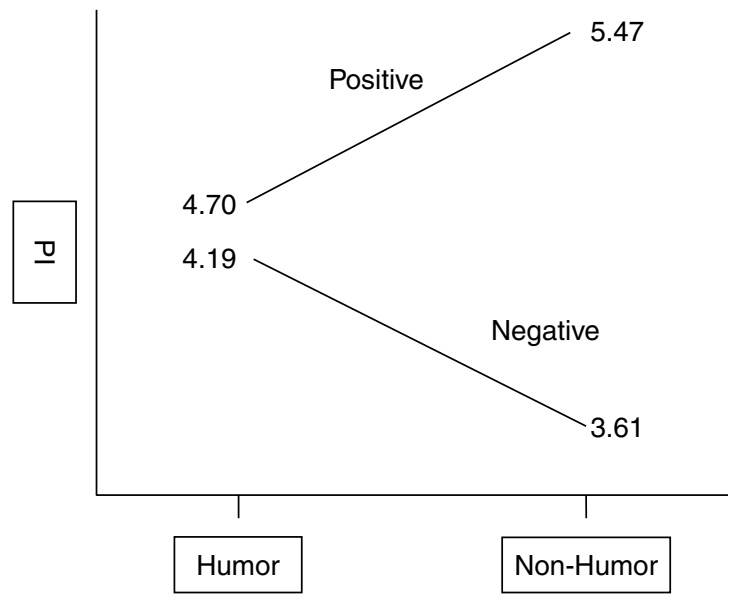

Figure 2: Purchase intention positive versus negative prior brand evaluation

placement in a movie. This study's possible contribution is threefold: to help assess the role of prior brand evaluation on consumer decision making; to help measure the impact of humorous messages and scenes that provide useful insight for this area and to help provide information on the role that prior brand evaluation and humour play in decision making. 
The results of the interaction effect revealed that peoples who are exposed to humorous movies scenes are likely to have a favourable attitude towards the brand and purchase behaviour when they have a positive prior brand evaluation. This study, however, did not find the interaction on emotional response and perception of product placement. This means that no correlation exists between the prior brand evaluation and types of movie scenes on emotional response and perception of product placement.

In the analysis of the main effect, the overall impact of humorous product placement in a movie on consumer emotions, such as arousal and pleasure, as well as the level of prior brand evaluation during the decision-making stage were analysed. The results are consistent with previous studies on the impact of humour. As seen, the results of this study, consumers prior brand evaluation would be based on their cognitive efforts and humorous placement associated with their affection.

These findings are associated with previous studies on product placement. Humorous placement of the product in a movie affects consumer's purchase intention. Product placement has been used to replace the strategy of traditional advertising. Given the previous discussion, product placement should be recognised as an alternative advertising strategy as well as a potential strategy for traditional advertising. Given the definition of product placement, products or services placed in movies for promotional purposes could appropriate an alternative communication strategy. Like the Gupta and Lord ${ }^{70}$ findings, prominent appearance of a product brought better consumer recall as compared to television commercials and more-subtle appearances of the product. Consequently, marketing and advertising communication should be considered as product placement replaces the strategy of traditional advertising. This study suggests that future studies should examine the relationship between types of movie (eg comedy, animation and action genre) and consumer attitude formation, as well as brand recall and recognition.
Our results closely parallel to those of Chattopahyay and Basu's. ${ }^{71}$ In addition to prior brand evaluation, the framed humorous placement is a more-effective persuasion tool for those who have negative prior evaluation towards the product. Humour can be considered a persuasive tool, and further research should investigate various kinds of humour that can have an impact on marketing application and consumer behaviour.

Product placement as an advertising communication strategy might be limited to fully controlling the presentation of products in movies and television programmes. It is difficult to generalise the movie scenes as the experimental stimuli in this study or to conduct wholly valid experimental research on product placement. To test the effects of product placement, more viewer exit surveys and experiments that can determine which brands actually were noticed during the movie showing should be done. It is anticipated that the analysis resulting from this valuable study will provide an archive of significant spectrum results for further empirical and theoretical studies on the role and affect of product placement as an alternative advertising strategy.

There is concern about the limitations of the sample segment in this study. The consumer segmentation may not be as representative as it could be because the sample used in this study comprises only college student sample of the US. In addition, the sample was limited to college students, who may exhibit different perceptions of the placement of the product in films than those of other consumer segments. Therefore, this study suggests that a future study should replicate the current study with a larger and more representative sample. Also, the data were collected in a convenience sampling of college students, which may have resulted in sampling biases; therefore, future studies applying these results to theoretical models on the effect of the placement of the product in film should compare results between consumers from different countries and cultures. As stated above, the consumer segmentation may be limited because of the sample used in this study. Along with a limited geographical region, another limitation of this 
study is that it did not fully cover various consumers (consumers below 20 years old and senior consumers). Moreover, education level and household income were also limited in this study since actual film media or can be assumed to be different for consumers who have different education levels and income.

In order to explore deeply the effect of the placement of the prodcut in cross-cultural study, future studies should focus on different perceptions of the placement of the product in film by exploring attitudes towards product placement, ethically charged products, acceptance rate and purchase behaviour of products shown in movies than consumer in different countries. In addition, viewers' perceptions of product placement in film compared to other countries should be studied.

Given human mood states, the exploration of product placement could be useful in examining the relationship between various humorous movies mood effect because the mood effects. In turn, mood effects produced by watching humorous movies could be effectively used for product placement. This study suggests that future research related to product placement in movies should include exposure to entire movie or at least portions longer than what was used herein.

\section{References}

1 Aaker, D. A. (2000) 'Brand Leadership', The Free Press, New York, USA.

2 Meenaghan, T. (2001) 'Sponsorship and advertising: A comparison of consumer perceptions', Psychology and Marketing, Vol. 18, No. 2, pp. 191-215.

3 Keller, K. L. (2003) 'Strategic Brand Management: Building, Measuring, and Managing Brand Equity', 2nd edn, PrenticeHall, Upper Saddle River, NJ.

4 Gupta, P. B. and Lord, K. R. (1998) 'Product placement in movies: The effect of prominence and mode on audience recall', Journal of Current Issues and Research in Advertising, Vol. 20, No. 1, pp. 47-59.

5 Brennan, I., Dubas, K. M and Babin, L. (1999) 'The impact of product placement type and exposure time on brand recognition', International Journal of Advertising, Vol. 18, No. 3, pp. 323-337.

6 Gupta and Lord (1998) op. cit.

7 Brennan, et al. (1999) op. cit.

8 D'Astous, A. and Seguin, N. (1999) 'Consumer reactions to product placement strategies in television sponsorship', European Journal of Marketing, Vol. 33, No. 9/10, pp. 896-910.

9 Ibid.
10 Nelson, R. M. (2002) 'Recall of brand placements in computer/ video games', Journal of Advertising Research, Vol. 42, No. 2, pp. 80-92.

11 Russell, C. A. (2002) 'Investigating the effectiveness of product placements in television shows: The role of modality and plot connection congruence on brand memory and attitude', Journal of Consumer Research, Vol. 29, No. 3, pp. 306-318.

12 Baker, M. J. and Crawdoed, H. A. (1996) 'Product placement', in Edward, A. B. and Wagner, A. K. (eds), 'Proceedings of the 1996 Winter Marketing Educators' Conference', American Marketing Association, Chicago, p. 312.

13 Gould, S. J., Gupta, P. B. and Sonja, G. K. (2000) 'Product placements in movies: A cross-cultural analysis of Austrian, French and American consumers' attitudes toward this emerging, international promotional medium', Journal of Advertising, Vol. 29, No. 4, pp. 41-59.

14 Karrh, J. A., Frith, K. T. and Callison, C. (2001) 'Audience attitudes towards brand (product) placement: Singapore and the United States', International Journal of Advertising, Vol. 20, No. 1, pp. 3-24.

15 Baker and Crawdoed (1996) op. cit.

16 Gould, et al. (2000) op. cit.

17 Karrh, et al. (2001) op. cit.

18 Lazarus, R. S. (1991) 'Progress on a cognitive-motivationalrelational theory of emotion', American Psychologist, Vol. 46 (August), pp. 819-833.

19 Holbrook, M. B. and O'Shaughnessy, J. (1984) 'The role of emotion in advertising', Psychology and Marketing, Vol. 1, pp. 45-64.

20 Ibid.

21 Detenber, B. H., Simons, R. F. and Bennett Jr, G. G. (1998) 'Roll "em!: The effects of picture motion on emotional responses", Journal of Broadcasting \& Electronic Media, Vol. 42, pp. 113-127.

22 Lang, P. J. (1980) 'Behavioral treatment and bio-behavioral assessment computer applications', in Joseph, B. S., James, H. J. and Thomas, A. T. (eds), 'Technology in Mental Health Care Delivery Systems', Ablex, Norwood, NJ, pp. 119-137.

23 Osgood, C., Suci, G. and Tannenbaum, P. (1957) 'The Measurement of Meaning', University of Illinois Press, Urbana.

24 Greenwald, M. K., Cook, E. W. and Lang, P. J. (1989) 'Affective judgement and psychophysiological response. Dimensional covariation in the evaluation of pictorial stimuli', Journal of pyschophysiology, Vol. 3, pp. 51-64.

25 Edell, J. A. and Marian, C. B. (1987) 'The power of feelings in understanding advertising effects', Journal of Consumer Research, Vol. 14 (December), pp. 421-433.

26 Chattopadhyay, A. and Basu, K. (1990) 'Humor in advertising: The moderating role of prior brand evaluation', Journal of Marketing Research, Vol. 27 (November), pp. 466-476.

27 Cho, H. (1995) 'Humor mechanisms, perceived humor and their relationships to various executional in advertising', Advances in Consumer Research, Vol. 22, pp. 191-197.

28 Sternthal, B. and Craig, S. (1973) 'Humor in advertising', Journal of Marketing, Vol. 37, No. 4, pp. 12-18.

29 Cho (1995) op. cit.

30 Osterhouse, R. and Timothy, B. (1970) 'Distraction increases yielding to propaganda by inhibiting counter-arguing', Journal of Personality and Social Psychology, Vol. 15 (August), pp. 344-358.

31 Scott, C., Klein, D. M. and Bryant, J. (1990) 'Consumer response to humor advertising: A series of field studies using behavioral observation', Journal of Consumer Research, Vol. 16, pp. 498-501.

32 Speck, P. S. (1987) 'On humor and humor in advertising', Unpublished doctoral dissertation, Texas Tech University. 
33 Zhang, Y. and Zinkhan, G. M. (1991) 'Humor in television advertising', in Rebecca, H. H. and Michael, R. S. (eds), 'Advances in Consumer Research', Vol. 18. Association for Consumer Research, Provo, UT, pp. 813-818.

34 Aaker, D. A., Douglas, M. S. and Michael, R. H. (1986) 'Warmth in advertising: Measurement, impact and sequence effects', Journal of Consumer Research, Vol. 12(March), pp. 365-381.

35 Zinkhan, G. M. and Gelb, G. D. (1990) 'Humor repetition and advertising effectiveness', in Marvin, E. G., Gerald, G. and Richard, W. P. (eds), 'Advances in Consumer Research', Vol. 17. Association for Consumer Research, Provo, UT, pp. 438-441.

36 Chattopadhyay and Basu (1990) op. cit.

37 Weinberger, M. G. and Gulas, C. S. (1992) 'The impact of humor in advertising: A review', Journal of Advertising, Vol. 21, pp. 35-59.

38 Gelb, B. D. and Zinkhan, G. M. (1985) 'The effect of repetition on humor in a radio advertising study', Journal of Advertising, Vol. 14, No. 4, pp. 13-20.

39 Stewart, D. and Furse, D. (1986) 'Effective Television Advertising', D.C. Health and Company, Lexington, MA.

40 Belch, G. E. and Belch, M. A. (1984) 'An investigation of the effects of repetition on cognitive and affective reactions to humorous and serious television commercials', in Kinnear, T. C. (ed), 'Advances in Consumer Research', Vol. 11. Association for Consumer Research, Provo, UT, pp. 4-10.

41 Duncan, C. P. and Nelson, J. E. (1985) 'Effects of humor in a radio advertising experiment', Journal of Advertising, Vol. 14, No. 2, pp. 33-40.

42 Gelb, B. D. and Pickett, C. M. (1983) 'Attitude-toward-the-ad: Links to humor and to advertising effectiveness', Journal of Advertising, Vol. 12, No. 2, pp. 34-42.

43 Ibid.

44 Madden, T. and Weinberger, M. (1984) 'Humor in advertising: A practitioner view', Journalof Advertising Research, Vol. 24, No. 4, pp. 23-29.

45 Sternthal and Craig (1973) op. cit.

46 Stewart and Furse (1986) op. cit.

47 Hoyer, D. W. and MacInns, D. J. (2001) 'Consumer Behavior', 2nd edn, Houghton Mifflin Company, Boston.

48 Sternthal and Craig (1973) op. cit.

49 Kelly, J. P. and Solomon, P. J. (1975) 'Humor in television advertising', Journal of Advertising, Vol. 4, No. 3, pp. 31-35.
50 Cacioppo, J. T. and Petty, R. E. (1979) 'Effects of message repetition and position on cognitive responses, recall, and persuasion', Journal of Personality and Social Psychology, Vol. 37, pp. 2181-2199.

51 Chattopadhyay and Basu (1990) op. cit.

52 Ibid.

53 Ibid.

54 Wu, C. and Shaffer, D. (1987) 'Susceptibility to persuasive appeals as a function of source credibility and prior experience with the attitude object', Journal of Applied Psychology, Vol. 52, pp. 677-688.

55 Dean, D. H. and Biswas, A. (2001) 'Third-party organization endorsement of products: An advertising cue affecting consumer prepurchase evaluation of goods and services', Journal of Advertising, Vol. 30, No. 4, pp. 41-57.

56 Zeitlin, M. D. and Richard, A. W. (1986) 'Measuring emotional response', Journal of Advertising Research, Vol. 26 (October/ November), pp. 34-44.

57 Chattopadhyay and Basu (1990) op. cit.

58 Ibid.

59 Ibid.

60 Lang (1980) op. cit.

61 Mehrabian, A. and Russell, J. A. (1974) 'A verbal measure of information rate for studies in environmental psychology', Environment and Behavior, Vol. 6, pp. 233-252.

62 Lang (1980) op. cit.

63 MacInnis, D. and Park, W. (1991) 'The differential role of characteristics of music on high- and low-involvement consumers' processing of ads', Journal of Consumer Research, Vol. 18, No. 2, pp. 161-173.

64 Haley, R. I. and Case, P. B. (1979) 'Testing thirteen attitude scales for agreement and brand discrimination', Journal of Marketing, Vol. 43(Fall), pp. 20-32.

65 Gormley, R. (1974) 'A note on seven brand rating scales and subsequent purchase', Journal of the Market Research Society, Vol. 16, No. 1, pp. 242-244.

66 Gruber, A. (1970) 'Purchase intent and purchase probability', Journal of Advertising Research, Vol. 10, No. 1, pp. 23-27.

67 Haley and Case (1979) op. cit.

68 Kassarjian, H. and Nakanishi, M. (1967) 'A study of selected opinion measurement techniques', Journal of Marketing Research, Vol. 4, pp. 148-153.

69 Chattopadhyay and Basu (1990) op. cit.

70 Gupta and Lord (1998) op. cit.

71 Chattopadhyay and Basu (1990) op. cit. 